\title{
Recovery from prolonged barbiturate sleep in the rat'
}

ROBERT A. LEVITT ${ }^{2}$

UNIVERSITY OF FLORIDA

Prolonged sleep was produced by periodic injections of pentobarbital. This sleep consisted predominantly of slow waves and spindles. No paradoxical sleep waves were observable in the cortex during the drug treatment. Following discontinuation of the drug, the amount of slow wave sleep decreased and paradoxical sleep increased when compared to a control period, suggesting a partial satiation of slow wave sleep and deprivation of paradoxical sleep by the treatment.

This experiment is concerned with the need for sleep; in particular with the susceptibility of sleep to satiation, with special reference to the two phases of sleep. Two phases of sleep thought to be qualitatively different have been delineated both in the human (Dement, 1965) and the rat (Swisher, 1962). The two phases in the rat are slow wave sleep (SWS) consisting of $1-3 \mathrm{c} / \mathrm{sec}$. activity with spindling, and paradoxical sleep (PS) consisting of $6-8 \mathrm{c} / \mathrm{sec}$. activity (Swisher, 1962). The paradoxical phase is thought to be analogous to Rapid Eye Movement (REM, dream) sleep in humans (Dement \& Kleitman, 1957).

The purpose of this experiment was to determine the effect of a $24 \mathrm{hr}$. period of pentobarbital induced sleep on subsequent sleep.

Method

Bipolar cortical electrodes (right frontal to occipital) were surgically implanted on the dura of four adult male Long-Evans rats. One week elapsed between surgery and beginning the experiment. EEG was recorded with a Grass III-D unit. The Ss were placed in individual cages in the experimental room $24 \mathrm{hr}$. prior to the beginning of recording; the first $6 \mathrm{hr}$. of EEG data were discarded as an additional adaptation period. The room was sound deadened, temperature was maintained at 67 to $69^{\circ} \mathrm{F}$., and the lights were on $12 \mathrm{hr}$. and off $12 \mathrm{hr}$, each day.

Waking, sWS, and PS were scored according to the criteria described by Swisher (1962). The control sleep cycle was recorded by EEG for $24 \mathrm{hr}$. Following this control period, sleep satiation was attempted by producing a prolonged sleep period lasting $24 \mathrm{hr}$. Pentobarbital sodium ( $40 \mathrm{mg} / \mathrm{kgm} \mathrm{IP)} \mathrm{was} \mathrm{injected} \mathrm{at} \mathrm{the}$ beginning of the drug period and then further injections were given whenever four consecutive waking minutes were present in the record. Injections were required approximately every 3-4 $\mathrm{hr}$. The drugged period was followed by $24 \mathrm{hr}$. of post-drug recording.

Resulis

The EEG during the drug period (satiation period) consisted almost entirely of slow waves and spindles similar to normal SWS in the rat, but with a higher frequency of spindles; no evidence of PS was present in the record. Small amounts of waking activity, a mounting to less than 10 per cent of the total record were present.

Table 1 summarizes the data from this experiment. During the satiation period the amount of waking and PS is significantly less than pre-and post-treatment and the amount of SWS is greater $(p<.001$ for all 6 comparisons).

When the pre-treatment day is compared to the posttreatment day, the decrease in SWS is significant $(p<.05)$, but the increases in amounts of waking and PS do not reach statistical significance. However, there was a significant increase in PS expressed as a percentage of total sleep during the post-treatment (recovery) period $(p<.01)$.

\section{Discussion}

The supression of PS during barbiturate induced sleep is in agreement with experiments using human $\mathrm{Ss}$, which have found barbiturates to depress REM sleep (Oswald, Berger, Jaramillo, Keddie, Olley, \& Plunkett, 1963). It is likely that the total depression found in this experiment in contrast to the limited depression in human Ss is due to the dosage differences (a sedative dose in the human vs. an anesthetic dose in the rat).

The finding of an increase in PS post-treatment is consistent with the supression of this phase during the satiation period. This increase in PS following its' deprivation has been found by other investigators (Dement, 1960; Siegel \& Gordon, 1965). Since barbiturate sleep does not mimic normal sleep but actually results in the deprivation of PS, a question would seem to be raised about this means of provoking sedation.

The idea that sleep functions as a need is supported both by the rebound increase in PS following its' deprivation and the decrease in SWS following satiation. The finding that barbiturate induced sleep consists of only one sleep phase and that SWS and PS respond

Table 1. A summary of the sleep cycle changes produced by pentobarbital - induced sleep.

Pre-Treatment Satiation-Period Post-Treatment

\begin{tabular}{lrrr}
\hline $\begin{array}{l}\text { Minutes } \\
\text { Waking }\end{array}$ & 790 & 135 & 838 \\
PS & 81 & 0 & 106 \\
SWS & $\frac{569}{1440}$ & $\frac{1305}{1440}$ & $\frac{496}{1440}$ \\
& 12 & 0 & 18 \\
\hline $\begin{array}{l}\text { PS as a per cent } \\
\text { of total sleep }\end{array}$ & 12 & 0 \\
\hline
\end{tabular}

Mean values for the four rats. 
differentially to this treatment lends support to the suggestion that there are at least two kinds of sleep; qualitatively distinct and subserving different functions (Dement, 1965; Jouvet, 1960).

\section{References}

Dement, w. The effect of dream deprivation. Science, 1960, 131, 1705-1707.

Dement, w. An essay on dreams: the role of physiology in understanding their nature. In New directions in psychology II. New York: Holt, Rinehart \& Winston, 1965. Pp. 135-257.

Dement, $\mathbf{W}$., \& Kleitman, $\mathbf{N}$. The relation of eye movements during sleep to dream activity: an objective method for the study of dreaming. J. exp. Psychol., 1957, 53, 339-346.

Jouvet, $M$. Telecephalic and thombencephalic sleep in the cat. In G. E. W. Wolstenholme \& M. O'Conner (Eds.), The nature of sleep. Boston: Little, Brown \& Co., 1960. Pp. 188-206.
Oswald, I., Berger, R., Jaramillo, R., Keddie, K., Olley, P., \& Plunkett, G. Melancholia and barbiturates: a controlled EEG, body and eye movement study of sleep. Brit. J. Psychiat., 1963, 109, 66-78.

Siegel, J., \& Gordon, T. P. Paradoxical sleep: deprivation in the cat. Science, 1964, 148, 978-980.

Swisher, J. Manifestations of "activated" sleep in the rat. Science, $1962,138,1110$.

\section{Notes}

1. The author wishes to express his gratitude to W. B. Webb for his comments and criticism. This investigation was supported by an NIMH grant (NIH-MH-03881-03) to W. B. Webb and by a NASA Predoctoral Fellowship (NASA-BSG(T)-13) to R. A. Levitt.

2. Now at the University of Pittsburgh. 